\title{
Multi-period portfolio selection model with transaction cost
}

\author{
CAI Jun \\ School of Economics and Management \\ Nanjing University of Science and Technology \\ Nanjing, China \\ caijun_516@163.com
}

\author{
MENG xiaolian \\ School of Economics and Management \\ Nanjing University of Science and Technology \\ Nanjing, China \\ mengx166@126.com
}

\begin{abstract}
In this paper, the possibilistic entropy model is introduced based on mean-semi variance model firstly. Then, the model was expanded to multi-period mean-semi variance possibilistic entropy model with transaction costs, taking the actual transaction costs and multi-period investment into account. Moreover, a numerical example was designed to prove the promotion performance of multi-period mean-semi variance possibilistic entropy model by using the stock data of Shanghai Stock Exchange, as well as carrying out coding and solving for the proposed model by using MATLAB software. The proposed model can provide decision basis and tools for investors.
\end{abstract}

Keywords-multi-period portfolio; mean-semi variance; transaction cost

\section{INTRODUCTION}

In order to find the optimum way of investing a particular amount of money in a given set of securities or assets, investors need to make decisions of allocating existing wealth to different assets so as to disperse losses and ensure benefits when choosing stocks, bonds in financial market. Investors and scholars have always paid much attention to make a tradeoff between risks and return with the best distribution of investment proportions so as to realize the maximum expected return as well as minimum expected risk.

Since Markowitz proposed the mean-variance (M-V) model of portfolio, scholars have proposed many extended portfolio models based on the basic mean-variation model, such as Giove (2006), Gupta (2008) and Xia (2000), etc. In reality, investment is a continuous process and investors have to adjust their investment strategies constantly, which require investigating portfolios elections as multiple-period or dynamic process in order to achieve maximum expected return. Li (2000) transferred mean-variation portfolio selections problem in multiple-period into a dynamic planning issue with embedded method, putting forward analytical optimal solution to the mean-variance formulation in multi-period portfolio selection. Yin (2004) studied a discrete-time version of Markowitz's mean-variance portfolio selection problem and derived correspondingly efficient portfolio and efficient frontier for the continuous time mean-variation portfolio. Briec (2007) proposed a nonparametric efficiency measurement approach for the static portfolio selection problem in mean-variance-skewness space and also establish a link to a proper indirect mean-variance-skewness utility function.

However, transaction cost may produce when adjusting existing portfolios by purchasing or selling assets. It is significant that transaction cost may affect the portfolio, which is a problem investor concern about. In general, there are comparatively less study on portfolio selective models with transaction cost for lack of optimum method. Morton (1995), Atkinson (1995) and Xia (2001) have conducted special treatment on trading fees since an accurate measurement of trading expenses may result in a minimum non-convex. For example, transaction costs were regarded as a constant and linear function or V-type function and so on.

Most portfolio selective models are established on the theoretical framework of possibility. But there are many non-possibility factors in real financial market, which lead to fuzzy and uncertain benefits of venture capitals. Zadeh proposed the fuzzy set theory in 1965, in which investors' subjective will and experts' knowledge are integrated into portfolio selections model. Carlsson (2002) took return as trapezoidal fuzzy numbers, and put forward portfolio models with fuzzy possibility based on the maximum utility function under short selling.

Fang (2003) proposed two portfolio rebalancing models with transaction costs based on fuzzy decision theory. Ida $(2003,2004)$ solved multi-objective portfolio selection problems with interval coefficients in Markowitz's framework. Zhang (2009) proposed a new portfolio selection model with the maximum utility based on the interval-valued possibilistic mean and possibilistic variance, which is a two-parameter quadratic programming problem. Bhattacharyya (2011) extended the classic mean-variation portfolio selection model with trading cost to mean-variation-skewness model with the concept of pitch fuzzy set theory. Liu (2013) have discussed the multi-goal portfolio optimization of actual portfolio selections under fuzzy environment.

Although some scholars have studied portfolio selec- 
tions problems under fuzzy environment, these are almost used to the single-period portfolio selection. Therefore, how to establish a multi-period portfolio selective model based on mean-variation model and taking transaction cost into consideration were explored This can provide theoretical basis and method for investors to make scientific investment decisions.

In this paper, a short discussion on fuzzy number is given in Section 2 and the possibilistic return, the possibilistic risk and the possibilistic entropy of multi-period portfolio were formulated. Based on these formulates, a bi-objective multi-period portfolio selection model was build, and then it was converted into a single goal programming model by using a simple weighted method. Then, a numerical example was designed to prove the performance of multi-period mean-semi variance possibilistic entropy model by using the stock data of Shanghai Stock Exchange in Section 3. Finally, some conclusions are specified in Section 4.

\section{THE FORMULATION OF MULTI-PERIOD PORTFOLIO}

\section{SELECTION MODEL WITH TRANSACTION COSTS}

The multi-period portfolio selection problem with $n$ risky assets is discussed, in which the return rates of risky assets are described as fuzzy variables. A set of symbols used are defined as follows in order to describe the model in a simple way.

$\omega_{t, i}$ the investment proportion of risky asset $\mathrm{i}$ at period $\mathrm{t} ; \omega_{t}$ the portfolio at period $\mathrm{t}$, where $\omega_{t}=\left(\omega_{t, 1}, \omega_{t, 2}, \ldots, \omega_{t, n}\right) ; R_{t}$ the return rate of the portfolio $\omega_{t}$ at period $\mathrm{t} ; \quad N_{\mathrm{t}}$ the net return rate of the portfolio $\omega_{t}$ at period $\mathrm{t} ; M_{t}$ the crisp form of the holding wealth at the beginning of period $\mathrm{t} ; p_{t, i}$ the unit cost of purchasing the risky asset $i$ at period $\mathrm{t} ; s_{t, i}$ the unit cost of selling the risky asset $\mathrm{i}$ at period $\mathrm{t}$.

\section{A. Return and Risk of Multi-period Portfolio Selection}

on the Basis of Fuzzy Numbers

$$
\begin{aligned}
& \qquad M_{t}=M_{t-1}\left(1+N_{t-1}\right) \\
& =M_{t-1}\left(1+E\left[\sum_{i=1}^{n} \omega_{t, i} r_{t, i}\right]-\sum_{t=1}^{n}\left[p _ { t , i } \left(\omega_{t, i}\right.\right.\right. \\
& \text { According to Zhang and Wang (2007), the lower pos- } \\
& \text { sibilistic semivariance } \operatorname{Var}^{-}\left(N_{t}\right) \text { of the portfolio } \omega_{t} \\
& \text { can be written as } \\
& \operatorname{Var}^{-}\left(N_{t}\right)=\sum_{i=1}^{n} \omega_{t, i}^{2} \operatorname{Var}^{-}\left(r_{t, i}\right)+2 \sum_{i<j=1}^{n} \omega_{t, i} \omega_{t, j} \operatorname{Cov}^{-}\left(r_{t, i}, r_{t, j}\right)
\end{aligned}
$$

Assume that the investor intends to allocate his wealth among the $\mathrm{n}$ risky assets for making $T$ period's investment plan, and his wealth can be reallocated among the n risky assets at the beginning of the following $T-1$ consecutive time periods.

According to Carlsson and Fullér (2001), the return rate of the portfolio $\omega_{t}$ at period $t$ is determined by

$$
R_{t}=E\left[\sum_{i=1}^{n} \omega_{t, i} r_{t, i}\right]
$$

Where the return rate $\mathrm{r}_{t, i}$ is fuzzy variable and $\omega_{t, i} \geq 0$.

Further, assume that the transaction cost is a V-shaped function of differences between the $t$ th period portfolio $\omega_{t}=\left(\omega_{t, 1}, \omega_{t, 2}, \ldots, \omega_{t, n}\right)$ and the $\mathrm{t}-1$ th period portfolio $\omega_{t-1}=\left(\omega_{t-1,1}, \omega_{t-1,2}, \ldots, \omega_{t-1, n}\right)$. Hence, the total transaction cost of the portfolio $\omega_{t}=\left(\omega_{t, 1}, \omega_{t, 2}, \ldots, \omega_{t, n}\right)$ at period $t$ can be expressed as

$$
\begin{gathered}
C_{t}=\sum_{t=1}^{n}\left[p_{t, i}\left(\omega_{t, i}-\omega_{t-1, i}\right)^{+}+s_{t, i}\left(\omega_{t, i}-\omega_{t-1, i}\right)^{-}\right] . \\
\text {Where }\left(\omega_{t, i}-\omega_{t-1, i}\right)^{+} \text {and }\left(\omega_{t, i}-\omega_{t-1, i}\right)^{-} \text {represent }
\end{gathered}
$$
the positive and negative parts of the function respectively.

Thus, the net return rate of the portfolio $\omega_{t}$ at period t can be expressed as

$$
N_{t}=E\left[\sum_{i=1}^{n} \omega_{t, i} r_{t, i}\right]-\sum_{t=1}^{n}\left[p_{t, i}\left(\omega_{t, i}-\omega_{t-1, i}\right)^{+}+s_{t, i}\left(\omega_{t, i}-\omega_{t-1, i}\right)^{-}\right] .
$$

Then, the crisp form of the holding wealth at the beginning of the period $t$ can be written as
Where $\operatorname{Var}^{-}\left(r_{t, i}\right)$ and $\operatorname{Cov}^{-}\left(r_{t, i}, r_{t, j}\right)$ represent the

B. Expression of Multi-period Portfolio Selection for

\section{Decentralized Investment}

One of the goals for investors is to reduce risks in the 
process of actual investment decision. At present, asset managers and researchers pay more attention to reduce risk by diversification for obtaining the optimal investment strategy because diversification can reduce the investment risk effectively. Some scholars used the proportion entropy measure the diversification degree of portfolio (such as Jana (2009)), and the mathematical expression is as the formula (1)

$$
\operatorname{En}(y)=-\sum_{i=1}^{n} y_{i} \ln y_{i}
$$

Where $y_{i}$ denotes as the investment proportion of asset $\mathrm{i}(\mathrm{i}=1,2, \ldots, \mathrm{n})$.

It shows that investors shall choose all assets to build a portfolio in Formula (1). However, investors may assign wealth to each asset in actual investment management, especially when the rate of return on investment $r_{i}$ of the assets of $\mathrm{i}$ was predicted to be less than the risk - free rate $r_{f}$, then investors may not invest the asset $i$. In that case, $y_{i}=0$, investors may not invest the asset $\mathrm{i}$, which contradict with the formula (1) above. Zhang (2012) proposed new possibilistic entropy to measure the diversification degree of the portfolio in the case of single period so as to overcome the shortcomings of proportion entropy.

Possibilistic entropy can be applied to multi-period portfolio selection problem to measure the diversification degree of investment portfolio. The possibilistic entropy of multi-period portfolio is shown as formula (2):

$$
P E_{m}(\omega)=-\sum_{t=1}^{T} \sum_{i=1}^{n}\left[\frac{\omega_{t, i} \theta\left(\omega_{t, i}\right)}{2} \ln \left(\varepsilon+\frac{\omega_{t, i} \theta\left(\omega_{t, i}\right)}{2}\right)+\left(1-\frac{\omega_{t, i} \theta\left(\omega_{t, i}\right)}{2}\right) \ln \left(1-\frac{\omega_{t, i} \theta\left(\omega_{t, i}\right)}{2}\right)\right]
$$

Where $\varepsilon$ is a sufficiently small positive number; $\max \left\{E\left(r_{i}\right)-r_{f}, 0\right\}$

$$
\text { represents the reward-to- variabil- }
$$

$$
\begin{aligned}
& \text { ity ratio of } \quad \text { asset } \quad \text { i } \quad ; \\
& \theta\left(\omega_{t, i}\right)=\frac{\max \left\{E\left(r_{t, i}\right)-r_{f}(t), 0\right\}}{\operatorname{Var}\left(r_{t, i}\right)} / \sum_{i=1}^{n} \frac{\max \left\{E\left(r_{t, i}\right)-r_{f}(t), 0\right\}}{\operatorname{Var}\left(r_{t, i}\right)}
\end{aligned}
$$

is the adjustment coefficient of $y_{i} ; r_{f}(t)$ is the risk-free return rate of the portfolio at period $\mathrm{t} ; E\left(r_{t, i}\right)$ and $\operatorname{Var}\left(r_{t, i}\right)$ denote as the possibilistic mean value and the possibilistic variance of the fuzzy return rate on asset $i$ at period $t$, respectively.

\section{Construction of the Multi-period Portfolio Selection Model}

Assume that investors are looking for a portfolio $\omega_{t}=\left(\omega_{t, 1}, \omega_{t, 2}, \ldots, \omega_{t, n}\right)$ to meet the three notes of investors: cumulative risk of investment portfolio is minimum, the diversification degree of the investment portfolio is maximum and investment return rate of each period met or exceeded the expected given minimum. The multi-period portfolio selection problem can be expressed as the following dual objective programming problem in order to satisfy the investors' demands, as model (M1) shows:

$$
M 1\left\{\begin{array}{l}
\min \sum_{t=1}^{T} \operatorname{Var}^{-}\left(R_{t}\right)=\sum_{t=1}^{T}\left[\sum_{i=1}^{n} \omega_{t, i}^{2} \operatorname{Var}^{-}\left(r_{t, i}\right)+2 \sum_{i<j=1}^{n} \omega_{t, i} \omega_{t, j} \operatorname{Cov}^{-}\left(r_{t, i}, r_{t, j}\right)\right] \\
\max P E_{m}(\omega)=-\sum_{t=1}^{T} \sum_{i=1}^{n}\left[\frac{\omega_{t, i} \theta\left(\omega_{t, i}\right)}{2} \ln \left(\varepsilon+\frac{\omega_{t, i} \theta\left(\omega_{t, i}\right)}{2}\right)+\left(1-\frac{\omega_{t, i} \theta\left(\omega_{t, i}\right)}{2}\right) \ln \left(1-\frac{\omega_{t, i} \theta\left(\omega_{t, i}\right)}{2}\right)\right] \\
\text { s.t. } E\left[\sum_{i=1}^{n} \omega_{t, i} r_{t, i}\right]-\sum_{t=1}^{n}\left[p_{t, i}\left(\omega_{t, i}-\omega_{t-1, i}\right)^{+}+s_{t, i}\left(\omega_{t, i}-\omega_{t-1, i}\right)^{-}\right] \geq r(t) \\
M_{t+1}=M_{t}\left(1+N_{t}\right) \\
\sum_{i=1}^{n} \omega_{t, i}=1 \\
\omega_{t, i} \geq 0, i=1,2, \ldots, n ; t=1,2, \ldots, T
\end{array}\right.
$$

However, this model has two conflicting goals: minimize the cumulative risk of the entire investment portfolio and maximize the diversification degree of investment portfolio in $T$ period. In order to find out a
Pareto optimal portfolio, we usually solve the optimization problem by maximizing a tradeoff between the two objectives. For the convenience of description, we define 
Therefore, to deal with the model by simple weighting method, the model (M1) has been transformed into model

$$
M 2\left\{\begin{array}{l}
\max -v \sum_{t=1}^{T} \operatorname{Var}^{-}\left(R_{t}\right)-(1-v) \sum_{t=1}^{T} \sum_{i=1}^{n}\left[\frac{\omega_{t, i} \theta\left(\omega_{t, i}\right)}{2} \ln \left(\varepsilon+\frac{\omega_{t, i} \theta\left(\omega_{t, i}\right)}{2}\right)+\left(1-\frac{\omega_{t, i} \theta\left(\omega_{t, i}\right)}{2}\right) \ln \left(1-\frac{\omega_{t, i} \theta\left(\omega_{t, i}\right)}{2}\right)\right] \\
\text { s.t. } \omega \in \varpi_{0}
\end{array}\right.
$$

$v \in[0,1]$ represents investors' preference coefficient. For different $v$, different importance of the objective function above can be given. If $v=0$, it means that maximizing the diversification degree of investment portfolio as a whole is the only selection of the investors, and investors dislike the concentrating investment strategy. If $v=0.5$, it indicates that investors have neutral attitude to both goals above; if $v=1$, it means that investors $t$ minimize cumulative risk of investment portfolio as a whole.

Model (M2) is a complex nonlinear programming problem, which is hard to find optimal solution with traditional optimization methods. Therefore, hybrid of genetic algorithm and Simulated Annealing Algorithm is selected to solve model (M2) in this paper.

\section{NUMERICAL EXAMPLES}

In order to express the idea of our model and the effectiveness of the designed algorithm, we give an example for simulating the real transaction. The example is a multi-period portfolio, a certain amount of stocks have been selected from Shanghai stock market data to simulate the whole investment process. Besides, with MATLAB software, the model is encoded and solved. Meanwhile, the transaction cost has been considered to make the model more close to reality. But dividing transaction cost into purchasing fees and selling fees makes the model more difficult to be solved. However, it is more suitable for investment decision makings
In this example, we consider a four-period portfolio selection problem with triangle fuzzy return rates. We assume the financial market has 4 risky assets for trading and investor's initial wealth is 10000 dollars, i.e. $\mathrm{W}_{1}=10000$.

If the investor selects six stocks with 10 thousand yuan for a three-period investment in the financial market, then $T=3$. And we set every four years as a period to handle their historical data. In order to simulate the transaction, we have collected the weekly closing prices of six stocks from Shanghai Stock Exchange between January 2002 and December 2013.We analyze data by taking four years as one observation period. Closing price of the latter day minus closing price of the former day is considered as difference value, and then this difference value divided by the former transaction closing price is the weekly yield of the stock. After dealing with the historical data of these assets by simple estimation method proposed by Vercher (2007), we can obtain trapezoidal possibility distribution of assets yield rate of each term.

The trapezoidal fuzzy benefits of six stocks in three different periods are shown in the table 1 . Since the trapezoidal fuzzy benefits are calculated according to closing price on each Friday, they can reflect yield condition of stocks in each period indirectly. From the table 1, we can see that return of the six stocks in the first period and the third period are worse than the second return, indicating return of the whole stock market present an increase and decrease trend.

\section{A. Data Acquisition and Processing}

TABLE I. THE RETURN RATES ON ASSETS OF THREE PERIODS INVESTMENT

\begin{tabular}{|c|c|c|c|}
\hline No. & $\boldsymbol{t}=\boldsymbol{1}$ & $\boldsymbol{t}=\mathbf{2}$ & $\boldsymbol{t}=\mathbf{3}$ \\
\hline 1 & $(-0.021,0.002,0.085,0.091)$ & $(0.025,0.100,0.140,0.189)$ & $(-0.013,0.010,0.078,0.082)$ \\
\hline 2 & $(-0.012,0.008,0.060,0.056)$ & $(0.019,0.074,0.133,0.180)$ & $(-0.007,0.009,0.044,0.034)$ \\
\hline 3 & $(-0.021,0.002,0.085,0.055)$ & $(0.027,0.052,0.117,0.225)$ & $(-0.013,0.013,0.090,0.095)$ \\
\hline 4 & $(-0.013,0.007,0.091,0.087)$ & $(0.019,0.068,0.019,0.140)$ & $(-0.019,0.013,0.098,0.133)$ \\
\hline 5 & $(-0.013,0.003,0.075,0.062)$ & $(0.029,0.063,0.136,0.161)$ & $(-0.009,0.017,0.102,0.113)$ \\
\hline 6 & $(-0.010,0.003,0.053,0.062)$ & $(0.019,0.130,0.161,0.291)$ & $(-0.013,0.009,0.049,0.060)$ \\
\hline
\end{tabular}

\section{B. The Results and the Analysis of the Model}

To solve this instance, the cost of the transaction costs in buying and selling stocks should be determined first. According to the Shanghai stock market trading fees, we let $p_{t, i}=0.003$ and $s_{t, i}=0.004(i=1,2,3,4,5,6 ; t=1,2,3)$. 
The risk-free return rates of the three period's investment are identical, as $r_{f}(1)=r_{f}(2)=r_{f}(3)=0.07$. The minimum expected return rates of the portfolio at periods 1,2 and 3 are set to $0.17,0.08$ and 0.08 , respectively. We apply the hybrid intelligent algorithm and the optimization software MATLAB to solve them. The parameters are set as follows:

the number of the chromosomes is 30 ; the probability of crossover operation is 0.8 ; the probability of mutation operation is 0.01 ; the initial temperature of simulated annealing is 500; the initial probability of acceptation is 0.8 ; the stop criterion is 0.0001 .

After running the algorithm 1000 iterations, the results are shown in Table 2.

TABLE II. THE RESULTS OF THE INSTANCES

\begin{tabular}{|c|c|c|c|c|c|c|c|c|}
\hline$v$ & $t$ & Stock 1 & Stock2 & Stock3 & Stock4 & Stock5 & Stock6 & Wealth \\
\hline \multirow{3}{*}{$\mathrm{v}=0$} & $\mathrm{t}=1$ & 0.1742 & 0.1678 & 0.1476 & 0.1044 & 0.1568 & 0.2492 & \multirow{3}{*}{10855.50} \\
\hline & $t=2$ & 0.1202 & 0.0273 & 0.0498 & 0.1570 & 0.1063 & 0.5395 & \\
\hline & $t=3$ & 0.1922 & 0.1731 & 0.0760 & 0.1475 & 0.2121 & 0.1990 & \\
\hline \multirow{3}{*}{$v=0.5$} & $t=1$ & 0.2005 & 0.1325 & 0.1684 & 0.1736 & 0.1702 & 0.1547 & \multirow{3}{*}{10742.80} \\
\hline & $t=2$ & 0.1303 & 0.0734 & 0.0872 & 0.1620 & 0.0271 & 0.5199 & \\
\hline & $t=3$ & 0.1705 & 0.2114 & 0.1433 & 0.1553 & 0.1837 & 0.1358 & \\
\hline \multirow{3}{*}{$\mathrm{v}=1$} & $\mathrm{t}=1$ & 0.3388 & 0.0354 & 0.3402 & 0.0785 & 0.1004 & 0.1067 & \multirow{3}{*}{10664.40} \\
\hline & $t=2$ & 0.0688 & 0.0580 & 0.0777 & 0.2786 & 0.0000 & 0.5169 & \\
\hline & $t=3$ & 0.1991 & 0.1195 & 0.1661 & 0.1785 & 0.1398 & 0.1970 & \\
\hline
\end{tabular}

The 1000 times of result of P2 model operated in MATLAB are shown in table 2 that According to table 2, the portfolio strategies in three periods with different preferred modulus are studied, that is $v=0,0.5,1$.

When $v=0$, it means that investor only considers maximizing the discrete degree of portfolios on the whole investment level, hating the concentrated investment strategy without considering investment risk. The investment strategies of the three periods investment obtained by $\mathrm{P} 2$ are

$$
\begin{aligned}
& x 1=(0.1742,0.1678,0.1476,0.1044,0.1568,0.2492) ; \\
& x 2=(0.1202,0.0273,0.0498,0.1570,0.1063,0.5395) ; \\
& x 3=(0.1922,0.1731,0.0760,0.1475,0.2121,0.1990) .
\end{aligned}
$$

The crisp form of the terminal wealth is 10855.5 yuan. In the first stage, the most amount of money was invested on the stock 6 , accounting for $24.92 \%$, after the second period, investor has changed his investment greatly with much more on stock 6 from the previous $24.92 \%$ to $53.85 \%$, accounting for more than a half capital. In the third period, the investor withdrew some money from stock 6 to invest on stock 1 , stock 2 and stock 5; while investment on stock 3 is still very low, indicating the wealth brought by stock 3 is far less than other stocks.

When $v=0.5$, it means the investor holds a neutral attitude towards the two goals above with fifty and fifty proportion of venture investment and investment diversification. Compared to $v=0$, the investment trend of the three periods is similar to the situation, while the only difference lies in that investment on stock 3 is increased slightly in the third period. The crisp form of the terminal wealth is 10742.8 yuan.

When $v=1$, it means the investor only hopes to minimize the accumulated risk of portfolios in the whole investment level without considering investment diversification. The investment strategies of the three periods investment obtained by $\mathrm{P} 2$ are

$$
\begin{aligned}
& x 1=(0.3388,0.0354,0.3402,0.0785,0.1004,0.1067) ; \\
& x 2=(0.0688,0.0580,0.0777,0.2786,0.0000,0.5169) ; \\
& x 3=(0.1991,0.1195,0.1661,0.1785,0.1398,0.1970) .
\end{aligned}
$$

The crisp form of the terminal wealth is 10664.40 yuan. Compared to $v=0$, the investment portfolios of stock 1 and stock 3 all exceed $30 \%$ in the first stage, which is far more than the investment portfolios of stock 1 and stock 3 under other two conditions, indicating stock 1 and stock 3 have lower risks in the first period. In particular, in the second period, the investment portfolio of stock 5 is 0 , indicating the yield of stock 5 in this period is lower than risk-free yield so that the investor gave up investment on stock 5.

When analyzing terminal wealth under the three conditions, we can see when $v=1$, the terminal wealth is the least; while when $v=0$, the terminal wealth is the most, which also indicates that high risk brings high wealth.

\section{CONCLUSION}

Multi-period investment portfolio selection problem with in transaction costs fuzzy environment was studied 
in this paper. We measure the return and the risks of multi-period portfolio by using possibility mean and possibility semi variance. In addition, considering the investors' willingness of diversification investment, we introduce the possibility entropy model to measure the diversification degree of portfolio.

In order to make the model more close to real, we have taken the transaction costs into account, and broke the transaction costs down into purchase costs and selling costs, then we use the mixture algorithm of genetic algorithm and simulated annealing algorithm to solve the proposed model. Finally, two numerical examples are given to illustrate the effectiveness of the proposed approach and the feasible of the designed algorithm.

\section{REFERENCES}

[1] S. Giove, S. Funari and C. Nardelli, "An interval portfolio selection problem based on regret function," European Journal of Operational Research, vol. 170, pp. 253-264, April 2006.

[2] P. Gupta, M.K. Mehlawat and A. Saxena, "Asset portfolio optimization using fuzzy mathematical programming," Information Sciences, vol. 178, pp. 1734-1755, March 2008.

[3] Y.S. Xia, B.D. Liu, S.Y. Wang and K.K. Lai, "A model for portfolio selection with order of expected returns," Computers \& Operations Research, vol. 27, pp. 409-422, April 2000.

[4] D. Li and W.L. Ng, "Optimal dynamic portfolio selection: Multiperiod mean-variance formulation," Mathematical Finance, vol. 10, pp. 387-406, July 2000.

[5] G. Yin and X.Y. Zhou, "Markowitz's mean-variance portfolio selection with regime switching: From discrete-time models to their continuous-time limits," IEEE Transactions on Automatic Control, vol. 49, pp. 349 - 360, March 2004.

[6] W. Briec, K. Kerstens and O. Jokung, "Mean-variance-skewness portfolio performance gauging: a general shortage function and dual approach," Management Science, vol. 53, pp.135-149, January 2007.

[7] A.J. Morton and S.R. Pliska, "Optimal portfolio management with fixed transaction costs," Mathematical Finance, vol. 5, pp. 337-356, October 1995

[8] C. Atkinson and P. Wilmott, "Portfolio management with transaction costs: an asymptotic analysis of the Morton and Pliska model," Mathematical Finance, vol. 5, pp. 357-367, October 1995.

[9] [9]Y. Xia, S. Wang and X. Deng, "A compromise solution to mutual funds portfolio selection with transaction costs," European Journal of Operational Research, vol. 134, pp. 564-581, November 2001.

[10] L.A. Zadeh, "Fuzzy sets, Inform and Control," 1965, pp.338-353.

[11] C. Carlsson and R. Fullér, "On possibilistic mean value and variance of fuzzy numbers," Fuzzy Sets and Systems, vol. 122, pp. 315-326, September 2001.

[12] Y. Fang, K.K. Lai and S.Y. Wang, "A fuzzy approach to portfolio rebalancing with transaction costs," Computational Science-ICCS 2003, vol. 2658, pp. 10-19, June 2003.

[13] ]M. Ida, "Portfolio selection problem with interval coefficients," Applied Mathematics Letters, vol. 16, pp. 709-713, July 2003.

[14] ]M. Ida, "Solutions for the portfolio selection problem with interval and fuzzy coefficients," Reliable Computing, vol. 10, pp. 389-400, October 2004

[15] W.G. Zhang, X.L. Zhang and W.L. Xiao, "Portfolio selection under possibilistic mean-variance utility and SMO algorithm,"
European Journal of Operational Research, vol.197, pp.693-700, September 2009.

[16] R. Bhattacharyya, S. Kar and D. D. Majumderb. "Fuzzy mean-variance-skewness portfolio selection models by interval analysis," Computers and Mathematics with Applications, vol. 61 , pp. 126-137, January 2011.

[17] Y.J. Liu and W.G. Zhang, "Fuzzy portfolio optimization model under real constraints," Insurance: Mathematics and Economics, vol. 53, pp. 704-711, November 2013.

[18] W.G Zhang and Y.L. Wang, "Notes on possibilistic variances of fuzzy numbers," Applied Mathematics Letters, vol. 20, pp. 1167-1173, November 2007.

[19] P. Jana, T.K. Roy and S.K. Mazumder, "Multi-objective possibilistic model for portfolio selection with transaction cost," Journal of Computational and Applied Mathematics, vol. 228, pp. 188-196, June 2009.

[20] W.G. Zhang, Y.J. Liu and W.J. Xu, "A possibilistic mean-semivariance-entropy model for multi-period portfolio selection with transaction costs," European Journal of Operational Research, vol. 222, pp. 341-349, October 2012. 